\title{
Effect of Change in Role of an Aircraft on Engine Life
}

\author{
A. Gad-Briggs \\ agbriggs@hotmail.co.uk \\ Department of Power and Propulsion \\ School of Engineering, Cranfield University \\ Bedford, United Kingdom.
}

\author{
A. Haslam \\ a.haslam@cranfield.ac.uk
}

\author{
P. Laskaridis \\ p.laskaridis@cranfield.ac.uk
}

\begin{abstract}
New aircraft require years of development from concept to realisation and can be prone to delays. Consequently, military operators take existing fleets and operate them in a different role. The objective of this study is to examine the effect of operating a typical low bypass military fast jet engine, originally designed for a European theatre, in a hot and harsh climate. The specific purpose is to determine the effect on the high-pressure turbine blade life and the life cycle cost of the engine.
\end{abstract}

A mission profile and respective performance conditions were analysed and modelled using an in-house performance tool. The flow conditions were simulated using ANSYS® FLUENT. A conjugated heat transfer solution was adopted to determine the blade metal temperature. The blade was modelled physically in 3D using SIMULIA® ABAQUS FEA software. The stresses were derived and used to calculate the temperature coupled low cycle fatigue and creep life.

A deterioration case was also studied to evaluate the effect of sand and dust ingestion. There was a significant life reduction of approximately $50 \%$ due to creep. The reduction in life was inversely proportional to the life cycle cost of the engine depending on the operating conditions. The results were compared with similar engines and summarised in the context of airworthiness regulations and component integrity.

\section{ABBREVIATIONS and NOTATIONS See main text.}

\subsection{INTRODUCTION}

Current demand for military fast jets is based on trends in defence spending after the September 2001 attacks in the US ${ }^{(1)}$. Although the 2008 financial crisis did put a halt on defence spending, acquisition of military aircraft during the 2009 Paris Air Show is an indication of such demand(2).

One solution to meet the demand is the conversion of the role of commercial aircraft. An example is the conversion of the VC10 and the Tristar aircraft into Air Refuelling (AR) and Air Transport (AT) roles respectively. The role of the aircraft changes the operating conditions of the engines. The engines could experience constant operation at off-design settings, with imposed conditions dictated by the specified military requirements.
This study examines the effects on a typical low bypass engine due to operation in a hot and high environment in the Middle East. This was achieved by defining a sortie in the relevant environment to simulate the engine design and off-design performance conditions. The flow conditions around the blade at the high-pressure turbine station was determined using Computational Fluid Dynamics (CFD). The study proceeded with an investigation of the thermal stresses coupled to the mechanical and fluid stresses induced in the highpressure turbine (HPT) blade. These were then used to study the temperature coupled low cycle fatigue (LCF) and creep life of the blade. It was then possible to estimate the change in the life cycle cost of the engine due to the reduced turbine life. The study provides an integrated approach to the estimation of a high-pressure turbine blade life.

\subsection{ESTABLISHING THE NEED FOR HPT BLADE LIFE ESTIMATION}

The two main performance parameters affected during change in aircraft role are the temperatures and pressures within the engine. The effect of such changes within the gas path could lead to an increase or decrease in thermal, velocity and pressure gradients. Adverse performance changes in the gas path could be detrimental to blade integrity. This would attribute to increased centrifugal stresses and thermal loading due to the longer time at temperature in the blade. The percentage of cooling air available for a given mass flow and the increased rotational speed to achieve the mass flow also has an impact on life. Operating the engine in alternative environments means the life of the blade will probably change from the originally predicted cyclic life.

\subsection{DERIVING A LOW FIDELITY APPROACH AND THE AIRCRAFT SORTIE}

Research carried out by Smith(3) whilst investigating a creep-based approach to gas turbine blade conceptual design, provided a foundation on which a framework is defined (see Fig. 1).

The sortie (Fig. 2) was derived from work carried out at Cranfield University, which focused on the design of a low bypass military fast jet engine. Other contributions came from researchers ${ }^{(4),(5),(6)}$ concerned with flight studies simulating psychological and mental capabilities at air-to-air and air-to-surface conditions. 


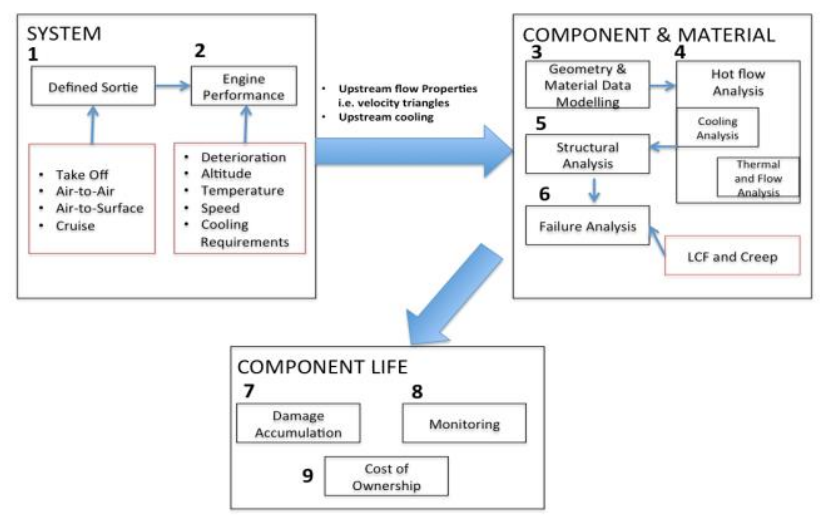

Fig. 1 - Low Fidelity Model

The sortie consists of the following:

Altitude: High speed and high thrust required to reach a reference altitude in a short time and to fly to the target location. The need for high speed and thrust requires maximum temperature, which is detrimental to blade life although operating conditions are mitigated by altitude.

Air Manoeuvres: Characterisation of the manoeuvres is evident in the throttle movements adopted at the altitude range for a given environment.

Air-to-Surface Attack: This is likely to take place at low altitude and would involve deployment of on-board weaponry.

Operational Scenario: As an example, the alternative location is assumed to be close to Kandahar Airport in Afghanistan. It is classed as hot and higher at over 1000 metres above sea level in a sandy desert terrain. The average yearly temperature is $\mathrm{ISA}^{*}+18.6^{\circ} \mathrm{C}\left(33.6^{\circ} \mathrm{C}\right)$. The effect of operating in Kandahar could also lead to changes in engine mass flow due to sand ingestion. Thus a deterioration case was considered within the flight profile at ground level.

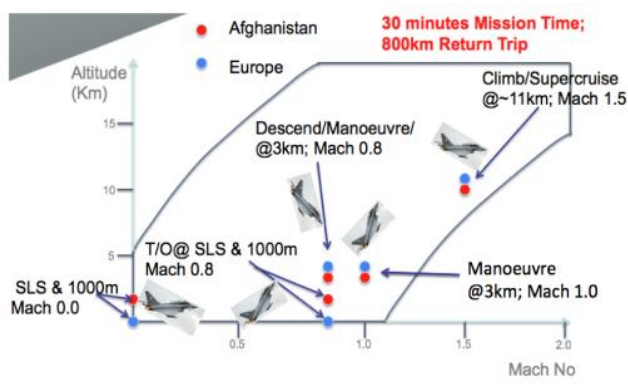

Fig. 2 - Mission Sortie Specification

\subsection{ENGINE SIMULATION AND BLADE MODELLING}

Performance Simulation: The overall engine performance due to change in role in relation to normal operating conditions was investigated. An in-house performance simulation software (TURBOMATCH) was used to calculate the design and off design conditions with reference to Fig. 2. The new operating conditions were based on compressor map scaling using the design

* International Standard Atmosphere point as reference. This involves mass and energy balancing, achieved in a series of iterations used to match the engine components. Deriving the new conditions required the imposition of the changes in isentropic efficiency and non-dimensional mass flow represented as $\Delta \pi_{i} \times$ and $\Delta w \times$ respectively. The operations used to derive the new values are expressed as:

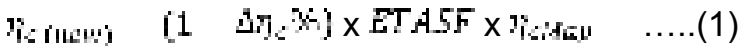

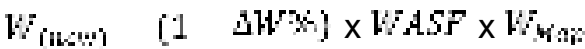

with ETASF and WASF representing scaling factors of $\Delta \pi \pi_{c} \times$ and $\Delta W \times$ respectively, which is created by the code, with reference to the compressor map within TURBOMATCH. Figure 3 presents the modelling schematic for a typical low bypass engine in TURBOMATCH. Table 1 shows the required engine parameters from the performance simulation, derived from 11 cases, encompassing 5 normal operating conditions (Europe), 5 alternative conditions (Kandahar) and 1 compressor flow deterioration case at ground level in Kandahar due to sand and dust ingestion (1\% flow impediment per compressor module).

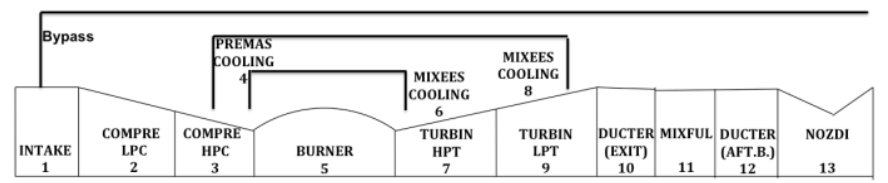

Fig. 3 - TURBOMATCH Designated Stations

Table 1. Required Parameters from Engine Simulation

\begin{tabular}{ll}
\hline Parameters & Comments \\
\hline $\begin{array}{l}\text { High Pressure } \\
\text { Compressor Exit } \\
\text { Temperature } \mathrm{T}_{4}\end{array}$ & $\begin{array}{l}\text { To estimate the coolant temperature } \\
\text { used to calculate the blade metal } \\
\text { temperature. }\end{array}$ \\
$\begin{array}{l}\text { Combustor Exit } \\
\text { Temperature } \mathrm{T}_{6}\end{array}$ & $\begin{array}{l}\text { To establish the mean combustor exit } \\
\text { temperature from the performance } \\
\text { drop due to cooling air mixing in the } \\
\text { gas path. Also required for the blade } \\
\text { aerodynamic calculations. }\end{array}$ \\
$\begin{array}{l}\text { Combustor Exit } \\
\text { Pressure } \mathrm{P}_{6}\end{array}$ & $\begin{array}{l}\text { Same as above but for pressure. } \\
\text { High Pressure } \\
\text { Turbine Entry } \\
\text { Temperature } \mathrm{T}_{7}\end{array}$ \\
$\begin{array}{l}\text { To calculate the blade metal } \\
\text { temperature and for the CFD analysis. }\end{array}$
\end{tabular}

High Pressure Turbine Entry

Pressure $\mathrm{P}_{7}$

High Pressure Turbine Exit Temperature $T_{8}$

Used to calculate the temperature drop in the turbine for the blade aerodynamic calculations.

High Pressure Turbine Exit Pressure $\mathrm{P}_{8}$
Used to calculate the pressure drop across the turbine for the blade aerodynamic calculations and blade bending stress calculations 
Previous research data from Cranfield University was utilised within the performance modelling. Based on this, the assumptions made in the performance modelling process were:

- Constant rotational speed throughout the flight segments of the sortie. This was kept at one hundred per cent and assumed to be $15000 \mathrm{rpm}$ for the highpressure spool.

- Cooling air of $10 \%-25 \%$ of mass flow, with a ratio of 1.5:1 - 2:1 ratio split between the HPT and LPT. Compressor and turbine efficiencies $\sim 80-85 \%$ and 85 $90 \%$ respectively. Combustor and afterburner efficiencies are $99 \%$ and $90 \%$ respectively. Duct losses are $5 \%$.

- A maximum Turbine Entry Temperature of over $1800 \mathrm{~K}$.

Figure 4 shows a set of temperature plots at the HPT entry location across the mission sortie (figure 2) for all conditions. The trend shows an upward increase in Kandahar, with a higher temperature observed during ground running when the mass flows at the LP and HP compressor inlets were impeded.

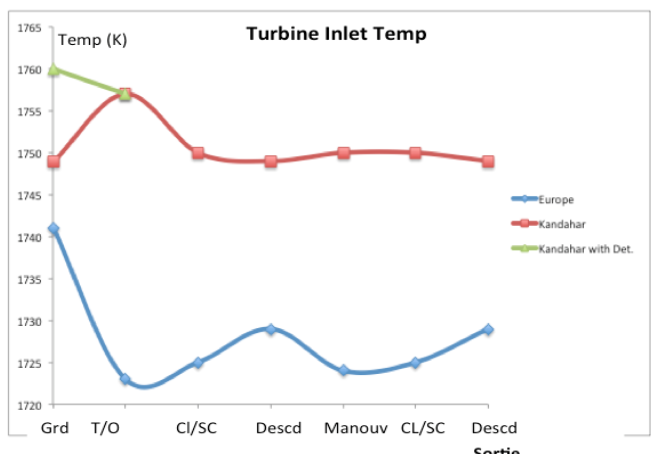

Fig. 4 - TET vs. Flight Segments (Sortie)

Glossary

Grd-Temp on ground/runway at max take-off power setting prior to take off (influenced by altitude).

T/O - Temp after successful take off and transition to max climb power setting.

CL/SC - Temp at transition from climb to super cruise power setting.

Descd - Temp at descend power setting.

Manouv - Temp during selected aircraft manoeuvres.

Aerodynamic and Blade Design: The guiding aerodynamic equations(7),(8) were used for the calculations with the velocity triangles being the main output (see Fig. 6). The aerodynamic assessment yielded $>50 \%$ reaction at the tip, $<50 \%$ reaction at the root and $50 \%$ reaction at mid height.

Blade Geometry Generation: The blade geometry was based on the output from the aerodynamic design. ANSYS $\circledast$ BLADEGEN was used to generate the blade geometry with a typical characterisation as shown in Fig. 5.

Figure 7 shows the output of the geometry design for the HPT rotor. The blades incorporate twists with the reaction based on the velocity triangles, which are outputs from the aerodynamic calculations (Fig. 6).

Fluid Analysis: The properties and behaviour of the hot gases are the major life limiting factors for the components aft of the combustor exit. This is due to the temperature gradient, pressure and momentum changes experienced on the blade surfaces. A 2D approach was adopted using ANSYS $\circledast$ GAMBIT to mesh the model and define boundary conditions. A non-dimensional wall value $(y+)$ of 1 was used to ensure that the near wall phenomenon of the flow was captured. This is characterised by the high Reynolds number experienced within the gas turbine.

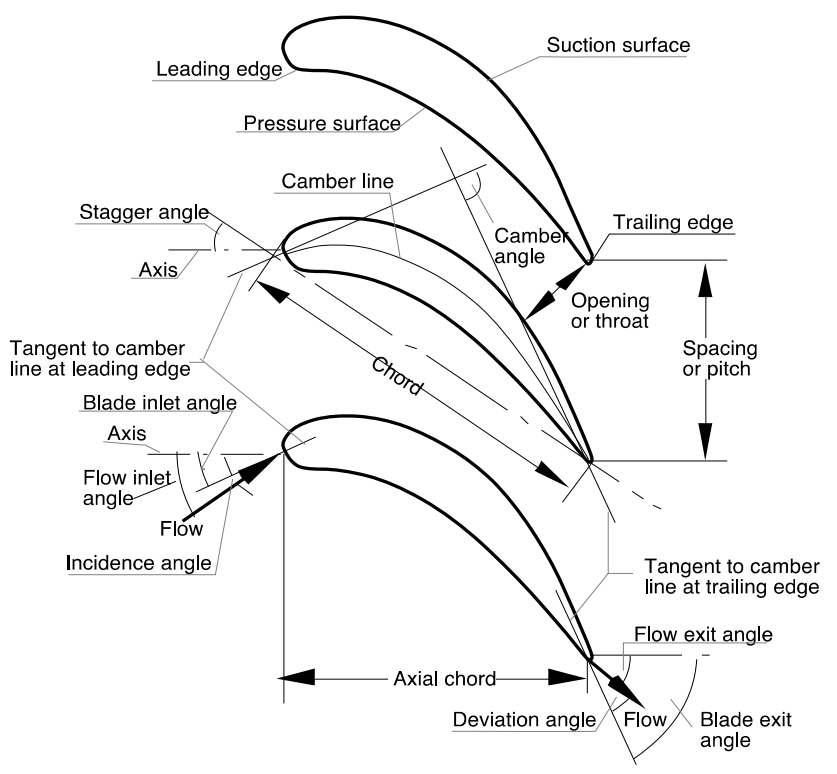

Fig. 5 - Typical Turbine Blade Characterisation ${ }^{(9)}$

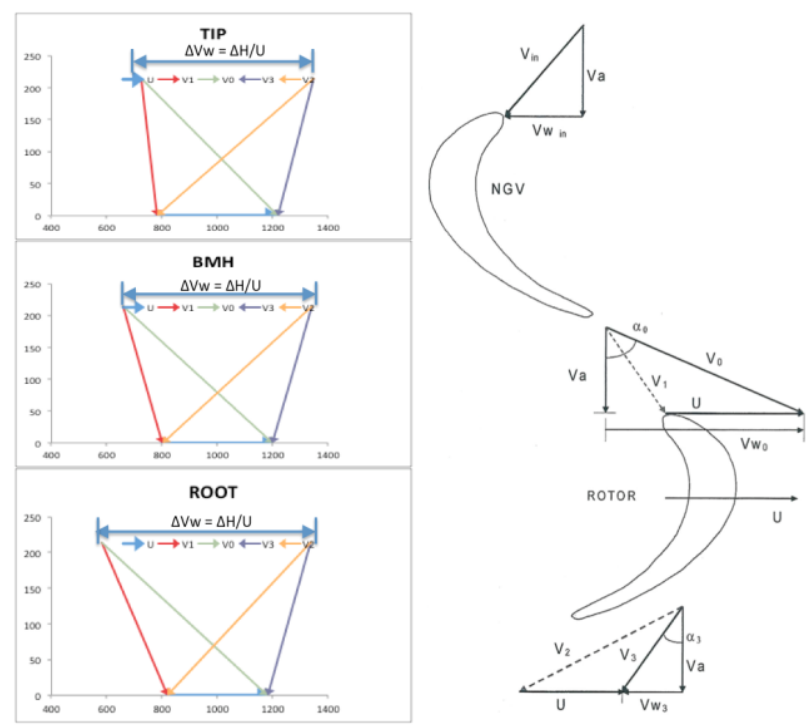

Fig. 6 - Velocity Triangles derived from Aerodynamic Calculations of the Subject Blade

ANSYS $\circledast$ FLUENT density based solver was used to solve the flow in a rotating frame cascade at the referenced rotational speed (RPM) adopted during the performance modelling. An implicit discretisation technique was adopted, which allowed for higher accuracy of the solution in steady state, due to a constant RPM. The cooling analysis was focused on estimating the blade metal temperature at the various flight conditions with High Pressure Compressor (HPC) air used for cooling in the inner blade wall, while the outer blade wall is exposed to the hot gas. 


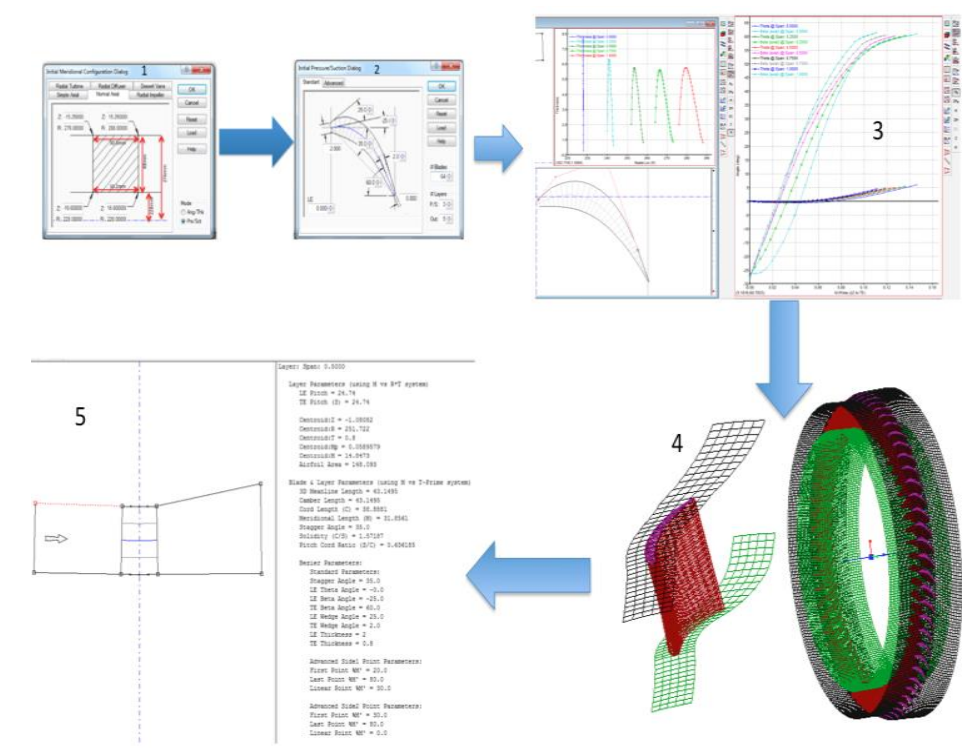

Fig. 7 - BLADEGEN Rotor Design Optimisation of the Subject Low Bypass Engine.

It was assumed that cooling is achieved through a combination of forced convection and film cooling. A cooling effectiveness between 0.55-0.65(10) representative of a typical low bypass turbine blade was assumed. The cooling effectiveness is expressed as:

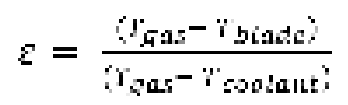

$T_{\text {cooinu: }}$ was assumed to be the temperature at the exit of the HPC, with $T_{p a ;}$ and $T_{\text {Lacs }}$ representing the hot gas at the turbine entry and outer surface metal temperature of the blade respectively. Thus the blade metal temperature was derived from equation 3 and imported to the CFD model.

The combustor temperature traverse quality affects the temperature profile along the span of the blade. The variables include the time of gas emergence from the compressor and the rate of change of the temperature within the combustion chamber, which is dependent on the mixing rate and the heat transfer process ${ }^{(11)}$. The heat transfer process and the variables are affected by the geometry of the liner and the pressure drop of the discharge into the dilution zone. In the absence of such detail, the typical traverse illustrated in Fig. 8 was adopted for the 2D approach.

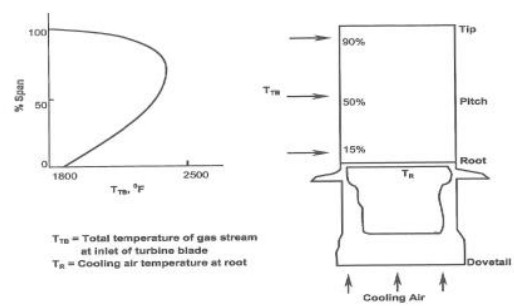

Fig. 8 - Typical Combustor Average Radial Profile(12)

The output from the cooling analysis was coupled with a thermal analysis to give the true blade metal temperature. The thermal analysis accounts for the heat flux to the blade outer wall in the CFD environment.
Material data such as coefficient of thermal expansion (CTE), thermal conductivity and density were specified. In the presence of a boundary layer, the moving fluid imparts heat to the solid blade surface and is expressed in terms of Newton's Law of Cooling as:

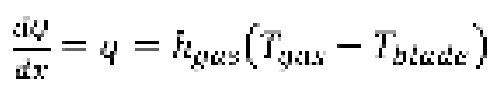

where $q$ is the heat flux and $i_{p a ;}$ is the mean convective heat transfer coefficient. However, the CFD environment accounts for the forced convection of flows. Thus the Stanton number represents the ratio of the heat transfer within the fluid to the thermal capacity of the fluid and is one of the key outputs of the CFD analysis. This is represented as:

$$
S I=\frac{\hbar}{e_{n} \rho v}=\frac{N u}{S s \cdot p r}
$$

where $V$ is the velocity of the fluid, $C_{n}$ is the specific heat at constant pressure, $R e$ is Reynolds number, $P r$ is Prandtl Number, $N u$ is Nusselt number and $\rho$ is density. Equation 5 represents the simplest of fundamental expressions for describing the heat transfer process. It is the energy transfer from a high temperature region due to thermal diffusion, which is common in the conditions of the gas turbine combustor exit. Figure 9 shows the performance of various turbulence models used within FLUENT. Comparison was made after a mesh independence study was undertaken. The main observation was that $K \omega$ and Transition SST provided better performance. In spite of identical results, it was decided to use the $K \omega$ turbulence model. The reason being the additional two transport equations also made it a more robust and adequate model for the flow assessment.

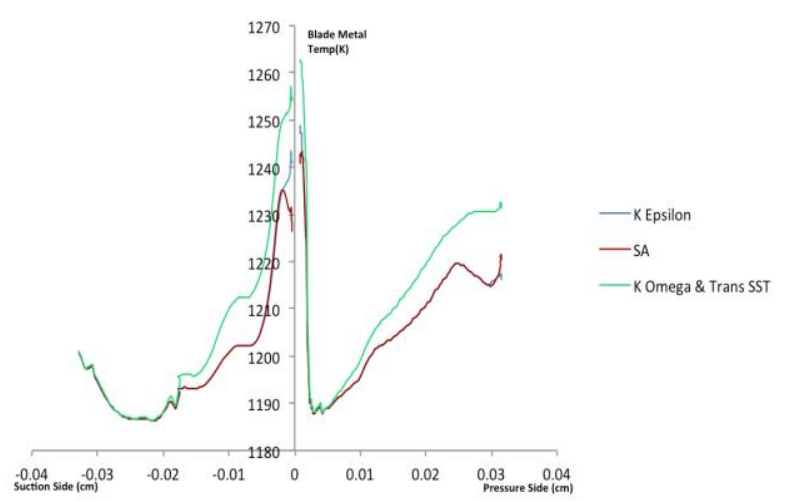

Fig. 9 - Blade Metal Temperature Comparison for the 'Descend Kandahar' Case

Figure 10, 11 and 12 illustrate typical trends in the study of the heat transfer coefficient, Stanton number and contours of Mach number. The trend observed is as expected for a typical turbine blade. The Stanton number and heat transfer coefficient are more pronounced at the leading edge because higher metal temperatures are experienced at the stagnation region. Figure 11 indicated that at $50 \%$ chord length on the suction surface, the Mach number was approximately 1.9 with flow separation observed. Aerofoil ps and ss denote the pressure and suction sides respectively. 


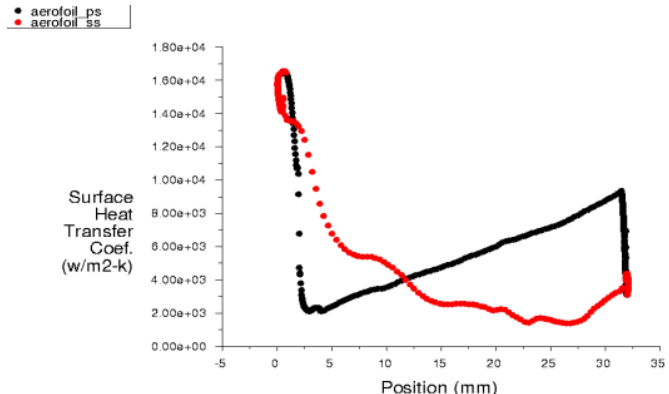

Fig. 10 - Surface Heat Transfer Coefficient

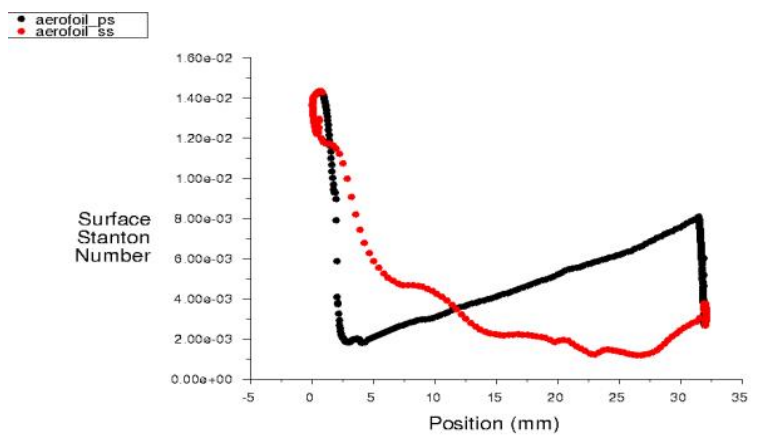

Fig. 11 - Surface Stanton Number

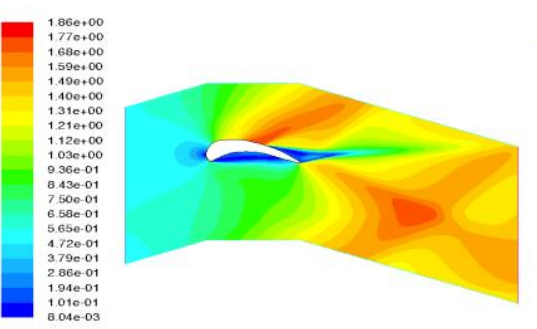

Fig. 12 - Contours of Mach Number

Figure 13 is an output chart for the take-off case in Kandahar showing the derived blade metal temperatures across the span for the pressure and suction sides. These were derived at $1 / 4$ span heights in accordance with the combustor temperature profile in fig. 8. The maximum temperature was assumed to occur at $75 \%$ span height, thus the metal temperature from the $2 \mathrm{D}$ CFD analysis was taken to be at $75 \%$ span height. To enable a realistic estimation of metal temperatures at the root, mid and tip, assumptions were made to derive the temperatures. They were estimated as a percentage of the maximum metal temperature established during the 2D CFD analysis. This approach was an improvisation in the absence of 3D CFD analysis. It enabled progression to the physical modelling phase in the FEA environment.

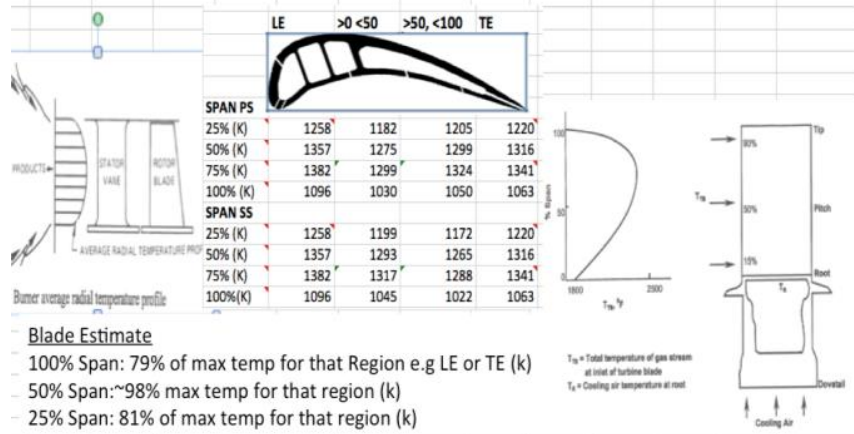

Fig.13 - Temperature Estimation of Blade at Take-Off in Kandahar
FEA Modelling: The blade FEA was conducted with the 3D blade. The blade was modelled using SIMULIA® ABAQUS.

The CMSX-4 material properties (where relevant) were established at 300 degrees kelvin as listed below $^{(13),(14),(15),(16)}$ and linearised to the specific temperatures for each case. The CMSX-4 material data was verified by the Materials Department at Cranfield University School of Applied Sciences and considered satisfactory for the study. The anisotropy of the structure was not considered due to availability of data.

- Thermal conductivity - 31.02 Watts per meter Kelvin (W/m K)

- Heat capacity - 0.960 Joules per Kilogram Kelvin (J/kg K)

- Density - 8.7 grams per cubic meter $(\mathrm{g} / \mathrm{cm} 3)$

- Thermal Expansion - $16.2 \times 10-6$ Length per Kelvin (I/K)

- Young Modulus (E) - 130 Giga Pascal (GPa)

- Shear Modulus (G) -130 Giga Pascal (GPa)

- $\quad$ Poisson's Ratio (v) - 0.39

- Yield Strength - 966 Mega Pascal (MPa)

- Ultimate Tensile Strength (UTS) - 1050 Mega Pascal (MPa)

Initial runs were set up and excluded the temperature on the blade. It was decided to impose all the derived loads to ensure the mathematical model was stable and the outputs were comparable to those observed on similar blade studies. An encastre set up to lock down the six degrees of freedom (DOF) points on the blades was adopted. The relationship between stress and the operating conditions of the physical blade profile is demonstrated in equation 6 .

$$
\sigma \propto A N^{2}
$$

where $A$ is cross sectional area and $N$ is the HP spool speed. The initial results were compared to hand calculations performed which assumed the blade to be a cantilever with a rectangular cross-section. The figures derived were comparable to that observed from the initial runs. The conditions imposed on the blade were adjusted in ABAQUS to account for shear stress on the blade surface. This was considered conservative but ensured the level of stresses observed were representative, prior to the temperature being added. This was considered satisfactory for the study.

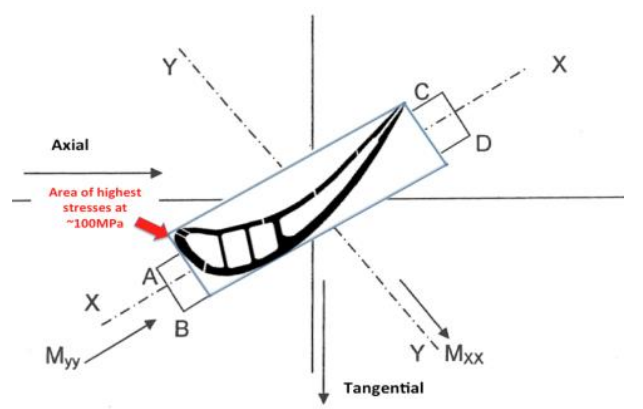

Fig. 14 - Area of Maximum Stress based on Hand Calculations 


\begin{tabular}{|l|r|}
\hline Blade Specifications & \\
\hline 0.2\% Proof Strength (Mpa) & $\mathbf{9 6 6}$ \\
\hline$\sigma_{\text {proot }}$ & $\mathbf{1 0}$ \\
\hline Thickness T(mm) & $\mathbf{3 1 . 8 5}$ \\
\hline Chord Length Lchord (mm) & $\mathbf{1 1 4}$ \\
\hline Root Radius rroot (mm) & $\mathbf{1 4 0}$ \\
\hline Tip Radius rtip (mm) & $\mathbf{8 7 0 0}$ \\
\hline Density kg/ $\mathbf{m}^{\text {s @300K }}$ & \\
\hline & \\
\hline RPM & $\mathbf{1 5 0 0 0}$ \\
\hline \#blades & 6 \\
\hline Mass Flow M (Kg/s) & $\mathbf{7 7}$ \\
\hline Dmean (mm) & $\mathbf{5 0 7}$ \\
\hline Dtip (mm) & $\mathbf{2 8 0}$ \\
\hline Dhub (mm) & $\mathbf{2 2 8}$ \\
\hline Radius Av(mm) & $\mathbf{2 5 3 . 5}$ \\
\hline Blade Mass (Kg) & $\mathbf{0 . 0 9 9}$ \\
\hline
\end{tabular}

The imposed blade metal temperatures derived from the CFD analysis indicated a maximum temperature of 1382 degrees Kelvin during take off in Kandahar, compared to 1310 degrees Kelvin take off temperature for the European mission. The deterioration case was imposed only on the ground due to sand ingestion in Kandahar.

Ground max power conditions, with a deteriorated compressor (flow impeded by $1 \%$ for each compressor) prior to take off resulted in a blade metal temperature of 1305 degrees Kelvin, which was higher by approximately 20 degrees Kelvin for the European case. All maximum blade metal temperatures were observed at the leading edge and were assumed to occur at approximately $75 \%$ of blade height based on the typical combustor temperature traverse described in figure 8 . The temperatures along the blade height were estimated as a percentage reduction from the temperature observed at $75 \%$ blade height as denoted in figure 13 .

Figure 15 illustrates the fight profile as modelled within ABAQUS in addition to time spent at each condition within the mission. This flight profile was assumed for the European and Kandahar cases.

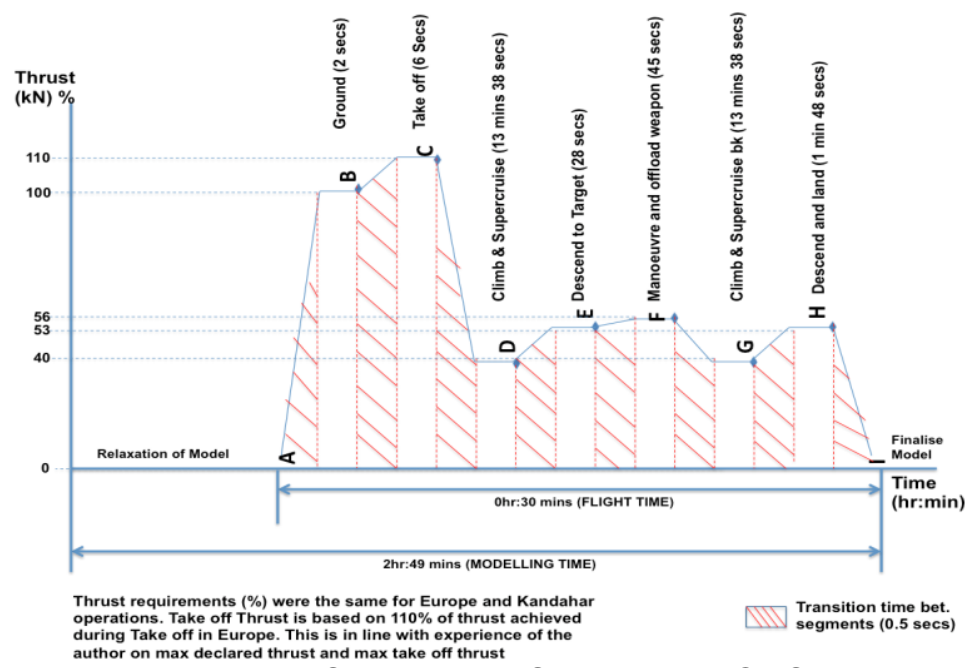

Fig. 15 - Flight Sortie Model Setup in ABAQUS

Figure 16 describes the stress evolution process on the blade, with the tip showing the higher stresses noticed on start-up due to the thermal shock, when compared to the mid and root. The greatest stresses were observed during take off. Stabilisation of running conditions brought about reduced stresses with fluctuations observed due to the modelled throttle exchanges.
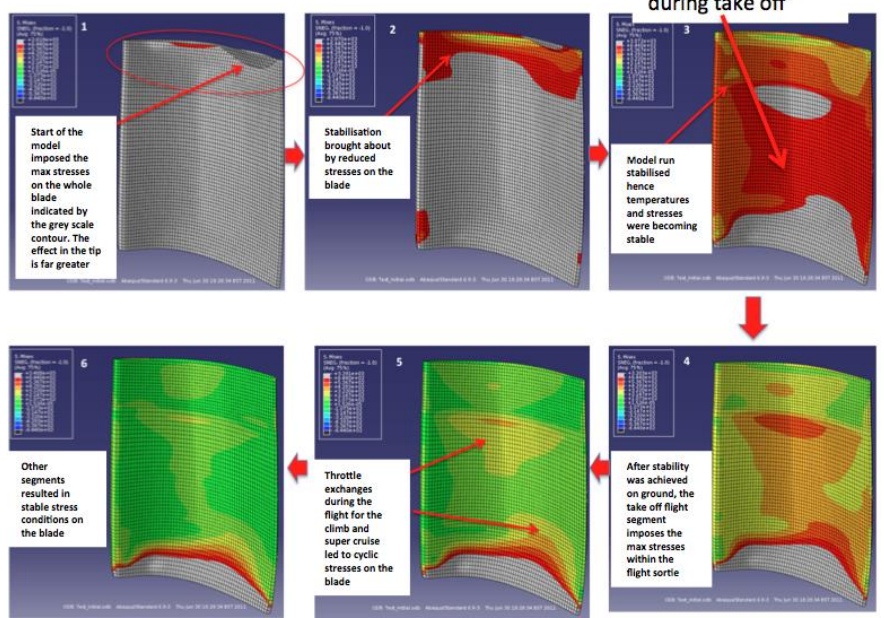

Fig. 16 - Blade Stress Evolution within the Flight Sortie

A scatter plot (fig. 17) was created based on stress and corresponding strain measurements taken during the three operating conditions for the sortie. The maximum stress within the area of interest (aerofoil geometry) was $650 \mathrm{MPa}$. An assessment was performed based on the scatter results to predict the curve from the point of plasticity to possible failure.

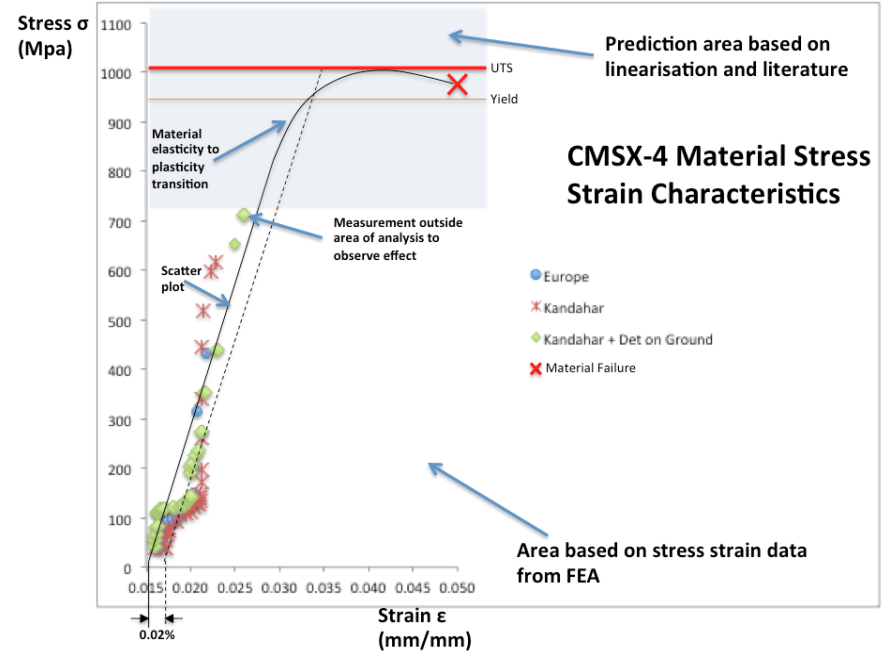

Fig. 17 - Stress Strain Analysis of CMSX-4

The purpose was to observe the effect on the strain characteristics. The highest stress for the deterioration case was on the ground due to sand and dust ingestion. The values are listed in Table 3 and are based on the simulation and material data, some of which were derived from assumptions.

From Fig. 17, it was concluded from a cyclic stress analysis that straining in areas of stress concentration is apparent, with possible deformation (shown in Table 3). There is also a time-temperature (creep) dependency due to the operating profile and time at temperature of the engine. Both observations supported the need to investigate temperature coupled low cycle fatigue and creep as the predominant failure modes. 
Table 3. Maximum Metal Temperature (Leading Edge), Maximum Nominal Stress and Strain

\begin{tabular}{|l|l|l|l|}
\hline Condition & $\begin{array}{l}\text { Max Metal } \\
\text { Temp }\end{array}$ & $\begin{array}{l}\text { Max Nominal } \\
\text { Stress }\end{array}$ & $\begin{array}{l}\text { Max Nominal } \\
\text { Strain }\end{array}$ \\
\hline Europe & $\begin{array}{l}{ }^{*} 1310 \mathrm{~K} \\
(1270 \mathrm{~K})\end{array}$ & $430(\mathrm{MPa})$ & $0.021(\mathrm{~mm} / \mathrm{mm})$ \\
\hline Kandahar & $\begin{array}{l}{ }^{*} 1382 \mathrm{~K} \\
(1280 \mathrm{~K})\end{array}$ & $550(\mathrm{MPa})$ & $0.022(\mathrm{~mm} / \mathrm{mm})$ \\
\hline Kandahar (Det) & $\begin{array}{l}{ }^{*} 1382 \mathrm{~K} \\
(1300 \mathrm{~K})\end{array}$ & $650(\mathrm{MPa})$ & $0.024(\mathrm{~mm} / \mathrm{mm})$ \\
\hline
\end{tabular}

${ }^{\star}$ Max metal temp post take off and transition to climb

()Max metal temp on grd at max power, prior to take off

\subsection{BLADE LIFE CALCULATION}

The Rainflow cycle counting method ${ }^{(17)}$, was used to calculate the temperature coupled low cycle fatigue. The approach employed a Goodman diagram (see Fig. 18), with a linearised approximated S-N curve for CMSX-4 based on research ${ }^{(15)}$ conducted for Rolls-Royce Deutschland.

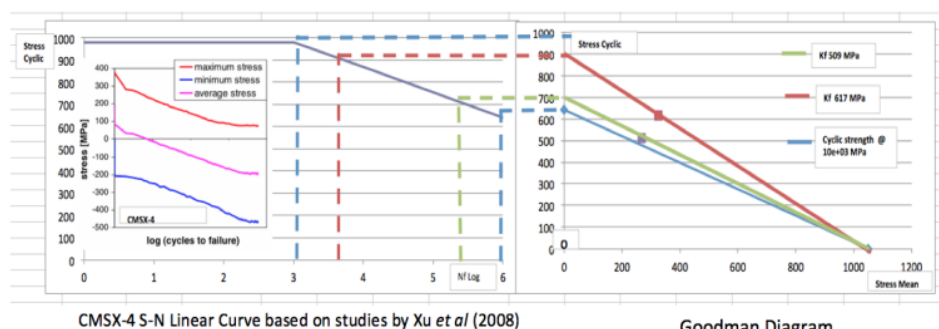

Fig. 18 - Goodman Diagram and S-N Curve

In the analysis of the time-temperature dependent aspect, the creep life was calculated using the LarsonMiller Parameter for the material in the conventional way.

\subsection{RESULTS AND DISCUSSIONS}

For the temperature coupled low cyclic fatigue cases, the damage accumulation of the number of cycles to failure is determined using the Palmgren-Miner rule. Similarly, the linear damage cumulative creep is derived using Robinson's rule.

The blade life for the temperature coupled low cycle fatigue, which includes the creep damage, is presented in table 4 . The reciprocals of the fatigue and creep values were added together. The inverse of the summation derived the Engine Flight Hours (EFH) for each operating point.

Table 4. Coupled Creep Fatigue Life - Engine Flight Hours (EFH)

\begin{tabular}{|l|l|}
\hline \multicolumn{2}{|l|}{ Rainflow (assumed CMSX-4 S-N Curve) } \\
\hline Environment & Engine Flight Hours \\
\hline Europe & 790 Hours \\
\hline Kandahar & 745 Hours 5\% drop in life \\
\hline Kandahar with Det. & 390 Hours $50 \% \pm 3 \%$ drop in life \\
\hline
\end{tabular}

Note: The EFH in this context represents a major overhaul and replacement of major components such as the turbine blade after these hours have been used up.

The values in table 4 with reference to the temperatures in table 3 , indicate that the increases in Turbine Entry
Temperature (TET) especially due to the compressor deterioration led to a reduction in life. When the LCF and creep cycles were combined, it was noticed that the final life was significantly reduced from the LCF life. This is because the creep life was significantly lower, which meant the total life was also low, in comparison to the LCF life. The turbine blade material therefore is greatly influenced by creep, in comparison to fatigue, at the defined sortie performance conditions. This is due to the operating time of the engine. However, high Turbine Entry Temperature (TET) is expected due to the adverse operating conditions within the mission profile. Deterioration was the dominant influence in accelerating the creep rate. One limitation during the lifing study was the lack of material data for CMSX-4, which could have been employed in other lifing techniques such as the Neuber and Manson approaches.

The Effect of Deterioration on The Life of the Engine: The effect of compressor flow deterioration was assessed using a flow impeding model within the performance modelling tool (TURBOMATCH). A reduction of $2 \%$ in compressor flow was imposed to simulate sand ingestion as discussed earlier. The overall effect was that the life was halved due to a temperature increase of 20 degrees Kelvin from the design point, which was required to meet the thrust requirements at ground altitude. It is not certain that this level of flow deterioration is ever experienced by such an engine inservice. However, the effect of some flow deterioration would result in other observations such as erosion on the compressor rotor aerofoils and stators due to debris, sand and dust. The performance of the compressor would therefore be degraded. Turbine degradation is also a possibility due to contamination of the secondary air system seals and recrystallisation of sand grains blocking cooling holes. Nevertheless, this study demonstrates that a compressor flow deterioration of $2 \%$, over a specific time period, could lead to a $50 \%$ reduction in the turbine blade life.

Cost of Ownership: With regards to the turbine module, it is assumed that the percentage reduction in life equates to the percentage increase in overall cost of ownership. However, the following information was derived from open sources on the operation of military fast jet aircraft in hot, dusty conditions:

Operations did lead to reduction in life and in some cases, operating the thrust reverser did result in ingestion of sand.

- The HPT blade life reduction of a similar engine had sometimes affected the on-wing life and overall life of the engine. Thus, a similar trend of a greater magnitude is to be expected for more modern engines due to the requirement for better engine performance and aircraft manoeuvrability.

- There are direct and indirect costs associated with replacing the components in a short time. The relationship used to express the cost increase based on life reduction only takes into account the direct costs. There are other costs associated with early retirement of components. Other problems identified from borescope inspection and non-destructive testing have to be rectified, which escalate the initial costs. 
- In the past, engines have experienced significant life reduction due to creep, which is in line with observations from the lifing calculations.

\subsection{CONCLUSION}

The investigation focused on the HPT blade typical of a low bypass turbofan gas turbine engine. The results of the study concluded that the life is reduced when operated in adverse climatic conditions. In fact, it was found that the life was halved, due to a temperature increase of 20 degrees Kelvin (to retain performance) from the intended operating condition. The conclusion that deterioration affects the life of the turbine blade is as expected.

The blades would therefore need to be replaced earlier than originally intended. Another aspect is that early replacements will lead to an increased cost of ownership. A more serious factor is that the life predicted for the old condition, is no longer applicable as long as the engine is operating in these new conditions. This is due to the uncertainly in the effect that such intense exposure will have on the structural properties of the material. Therefore, an investigation into improving the material integrity such as the use of novel thermal barrier coatings is required. Ideally, a change in operational requirements should initiate an investigation of the whole design and cooling process of the blade. The outcome could be an increase in mass flow to allow more cooling air availability. This would promote effective management of the engine airworthiness and ensure that the documentation is in line with new predictions.

The methods employed are detailed within the research thesis ${ }^{(18)}$ and offer alternatives to expensive testing procedures. From research of similar failure investigations, the outcomes as presented in all aspects are similar. However, it is perceived that it is in the interest of design authorities to ensure control and impose the life limitations necessary to avoid major inservice failures. An alternative would be to redesign a robust HPT for extreme conditions, which might be an expensive alternative. Finally, other damage mechanisms such as thermomechanical fatigue could also benefit from the detailed modelling. It provides an alternative approach, which, serves to enhance the existing lifing methods. The method also accounts for thermal transients resulting from start up and shut down and the accompanying mechanical strain.

\section{ACKNOWDGEMENTS}

The authors wish to thank the Department of Power and Propulsion, Cranfield University for acknowledging the research conducted and for providing the necessary support required to publicise this paper.

\section{REFERENCES}

Some of the research pieces referred to in this study are based on unpublished Cranfield University literature. This paper owes all statements, results and discussions to the subject thesis (referenced herein), which was completed as part of a postgraduate study at Cranfield University. With the exception of the subject thesis, the following references are in the public domain:
1. Corbin, M. E. A. (2003), Security After 9/11: Strategy Choices and Budget Tradeoffs, Center for Defence Information, Washington.

2. Matlack, C. (2009) "Defence on Center Stage at Paris Air show", Bloomberg Business Week, (Aviation), 15th June 2009.

3. Smith, M. E. B. (2008), A Parametric Physics Based Creep Life Prediction Approach To Gas Turbine Blade Conceptual Design (unpublished $\mathrm{PhD}$ thesis), Georgia Institute of Technology, Georgia, USA.

4. Lintern, G., Thomley, E., Nelson, B. E. and Roscoe, S. N. (1984), Content, Variety and Augmentation of Simulated Visual Scenes fort Teaching Air-to-Ground Attack, NAVTRAEQUIPCEN 81-C-0105-3, Department of the Navy, Naval Training Equipment Center, Orlando, Florida.

5. Magnusson, S. (2002), "Similarities and Differences in Psychophysiological Reactions Between Simulated and Real Air-to-Ground Missions", The International Journal of Aviation Psychology, vol. 12, no. 1, pp. 49-61.

6. Colle, H. A. and Reid, G. B. (2005), "Estimating a Mental Workload Redline in a Simulated Air-toGround Combat Mission", THE INTERNATIONAL JOURNAL OF AVIATION PSYCHOLOGY, vol. 15, no. 4, pp. 303-319.

7. Aungier, R. H. (2006), Turbine Aerodynamics: Axial-Flow and Radial-Inflow Turbine Design and Analysis, ASME, New York.

8. Fielding, L. (2000), Turbine Design; The Effect on Axial Flow Turbine Performance of Parameter Variation, ASME, New York.

9. Wilson, D. G. (1991), The Design of HighEfficiency Turbomachinery and Gas Turbines, 5th ed, MIT Press, Cambridge, Massachusetts.

10. Naeem, M., Singh R., Probert R. (1999), Implications of Aero-Engine Deterioration for a for a High-Pressure Turbine's Blade Low-Cycle Fatigue (LCF) Life Consumption, International Journal of Fatigue, Vol 21, Iss 08, pp 831-847.

11. Lefebvre, A. H. and Ballal, D. R. (2010), Gas Turbine Combustion - Alternative Fuels and Emissions, 3rd ed, CRC Press, USA.

12. Han, J. C., Dutta, S. and Ekkad, S. (2000), Gas Turbine Heat Transfer and Cooling Technology, Taylor and Francis, New York.

13. Matsushita, T., Fecht, H., J., Wunderlich R., K. and Seetharaman, S. (2009), "Studies of the Thermophysical Properties of Commercial CMSX-4 Alloy", Journal of Chemical Engineering, vol. 54, pp. 2584-2592. 
14. Jéhanno, P., Heilmaier, M., Kestler, H., Böning, M., Venskutonis, A., Bewlay, B. and Jackson, M. (2005), "Assessment of a Powder Metallurgical Processing Route for Refractory Metal Silicide Alloys", Metallurgical And Materials Transactions, vol. 36A, pp. 515-523.

15. Xu, J., Reuter, S. and Rothkegel, W. (2008), "Tensile and bending thermo-mechanical fatigue testing on cylindrical and flat specimens of CMSX-4 for design of turbine blades", International Journal of Fatigue, vol. 30, pp. 363371.

16. Nickel Development Institute (1995), HighTemperature High-Strength Nickel Based Super Alloys, Supplement no 393, Nickel Development Institute.

17. Suresh, S. (1998), Fatigue of Materials, Second Edition, Cambridge University Press, Cambridge, UK.

18. Gad-Briggs, A. (2011), Effect of Change in Role of an Aircraft on Engine Life (unpublished thesis), Cranfield University, Cranfield, UK. 


\title{
Cranfield University
}

\section{CERES https://dspace.lib.cranfield.ac.uk}

2017-05-03

\section{Effect of change in role of an aircraft on engine life}

\author{
Gad-Briggs, Arnold
}

Gad-Briggs A, Haslam A, Laskaridis P, Effect of change in role of an aircraft on engine life, The Aeronautical Journal, Vol. 117, Issue 1196, October 2013, pp. 1053-1070

https://doi.org/10.1017/S000192400000868X

Downloaded from Cranfield Library Services E-Repository 